\title{
Laser Wire Deposition of a Large Ti-6Al-4V Space Component
}

\author{
The methodology for creating a functional Ti-6Al-4V satellite \\ part using LWD additive manufacturing is detailed
}

\author{
BY N. CHEKIR, J. J. SIXSMITH, R. TOLLETT, AND M. BROCHU
}

\begin{abstract}
Additive manufacturing (AM) is an attractive solution for the aerospace industry to reduce cost processing, lead times, and material waste. Laser wire deposition (LWD) is a particular type of directed energy deposition (DED) process that can be used for AM applications. The main advantages of using LWD include large working envelopes, high deposition rates, and high-quality parts. This study took advantage of the extensive knowledge in the manufacturing of deposition processes and welding metallurgy provided by Liburdi Automation Inc. to print a large Ti-6Al-4V space component with different wall thicknesses. A LAWS 1000 automated welding system associated with multiple degrees of freedom was selected for this case study. The selected part, when fabricated using machining, had a buy-to-fly ratio (BTF) of 30.8. The AM methodology reduced this BTF to 3.2. This paper presents the undertaken methodology for this case study. The manufacturing strategy is also presented, followed by various nondestructive examination procedures used to control part compliance with the technical drawing requirements for postdeposition heat treatments. Destructive examination, including the investigation of the typical microstructure that developed within the part, and the mechanical properties of representative sections of the part, were performed. Finally, the machining strategy to the drawing requirements of the part was presented based on previous findings.
\end{abstract}

\section{KEYWORDS}

- Additive Manufacturing • Laser Wire Deposition

- Directed Energy Deposition - Ti-6Al-4V

- Heat Treatment • Nondestructive Examination

- Hardness - Mechanical Properties • Microstructure

- Machining • Static Tensile Testing

\section{Introduction}

Titanium alloys are extremely popular in the aerospace industry mainly for their high strength-to-weight ratio and corrosion resistance (Ref. 1). However, their high cost, in part induced by the use of conventional manufacturing processes, makes them hardly accessible for industries in- volving high levels of production (Refs. 2-4).

A change in the involved manufacturing processes could result in nonnegligible cost savings. Currently, most of these processes involve a combination of forging and subtractive operations, inducing substantial material waste and tooling wear (Ref. 1). The buy-to-fly (BTF) ratio is then a common tool used by the aerospace industry to assess the generated material waste of a particular manufacturing process (Refs. $1,5)$. The BTF is defined as being the weight of the initial bulk material divided by the weight of the final product. It is quite common to see this ratio reaching values comprised of 15 to 20 or higher (Ref. 1). Additive manufacturing (AM) is then seen as an attractive solution to reduce this ratio to values closer to 1 . Moreover, with the reduced lead times and generated waste, AM could be seen as a potential solution for manufacturing cost reduction.

This research focused on a particular type of AM process that belongs to the directed energy deposition (DED) group, namely the laser wire deposition (LWD) process. Laser wire deposition is associated with multiple advantages, such as high deposition rates, large working envelopes, and good part quality, among others (Refs. 6-8). Additive manufacturing of metallic parts is also known to generate near-netshape products, substantially reducing the BTF ratio. This paper presents all the steps to print a large part using Ti$6 \mathrm{Al}-4 \mathrm{~V}$, which is the most popular titanium alloy used in the aerospace industry (Ref. 1). First, selection of the part and printing strategy will be presented. Both nondestructive and destructive examination will then be performed to assess geometrical integrity, structural integrity, and the final properties of the printed part. All these steps eventually enable machining of the part to the drawing requirements.

\section{Experimental Methods}

Selection of the part to be printed was done jointly with MDA Corp., Canada, which specializes in the design and manufacturing of satellites and satellite subsystems. The selected part in Fig. 1A is a typical bracket used on their satellites. This part is about $152.4 \mathrm{~mm}$ tall, and would have a BTF close to 30.8 if conventional subtractive manufacturing processes were to be used. Parts were built using a LAWS 


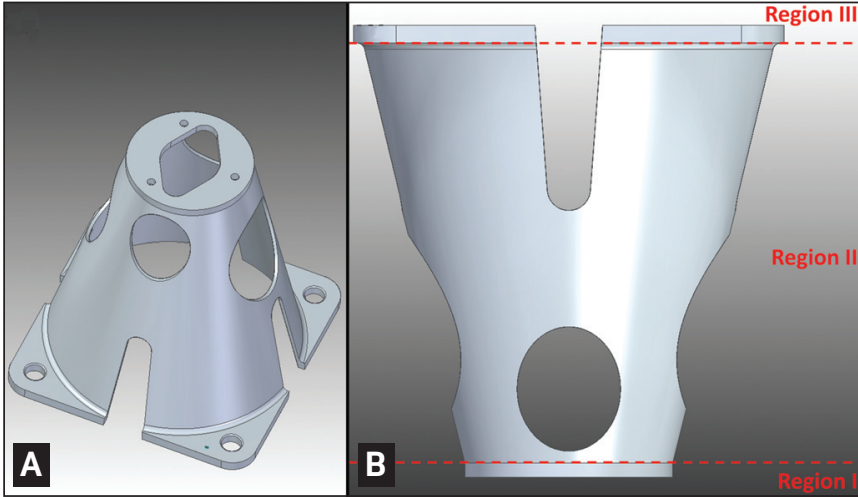

Fig. 1-A - CAD model of the selected space bracket; B identification of individual part geometries.

1000 automated deposition system (Liburdi, Hamilton, ON, Canada). The robot is controlled by WinLAWS, an in-house software allowing the operator to program axis movements along with defining customized deposition parameters. An IPG YLS-1000 Yb:YAG fiber laser (IPG Photonics, Oxford, Mass.) reaching up to $1 \mathrm{~kW}$ power was used to fuse the material. To prevent excessive oxidation, all deposits were completed in a custom-made argon purge box with oxygen levels below 60 ppm, monitored with a Series 3000 Trace Oxygen Analyzer (Alpha Omega Instruments, Lincoln, R.I.).

Wrought Ti-6Al-4V plates were used as starting substrates. A Ti-6Al-4V wire spool with extra-low interstitials (oxygen weight percentage being below $0.13 \%$ ) was used to deposit the material.

To take full advantage of the central symmetry of the selected part, the substrate was mounted on a rotary plate that can also tilt around the x-axis, as shown in Fig. 2A. Region II, as shown in Fig. 1B, had the geometry of a cone characterized by a thickness of about $1.1 \mathrm{~mm}$ and an angle of $14 \mathrm{deg}$. To optimize the printing process in this region, the substrate in Region I was tilted by the same amount as the cone angle around the $\mathrm{x}$-axis, as shown in Fig. 2B. As a result, the cone wall was built by a combination of a continuous rotation of the rotary plate around its rotary axis z" and an incremental increase of the laser head along the z-axis. Deposition parameters for this region were optimized in previous studies (Refs. 9, 10), resulting in a printing time of about $4 \mathrm{~h}$. A flange extending at the end of the printed cone characterized Region III. This flange is characterized by a thickness of $6.1 \mathrm{~mm}$. This requires the deposition of multiple beads within the same layer, as shown in Fig. 2C. Here, the part is tilted by 90 deg using the surface of the cone as a new substrate. The flange is then built by the combination of a continuous rotation of the rotary plate around its rotary axis z" and a coordinated move along the zand y-axes, as shown in Fig. 2C. Deposition parameters for this region were also optimized in a previous study (Ref. 11) associated with about $10 \mathrm{~h}$ of printing.

Samples were heat treated postdeposition with an annealing cycle just below the $\beta$ transus temperature followed by an aging cycle, both in agreement with the AMS2801, Heat Treatment of Titanium Parts, specification. More details can be found in previous studies (Refs. 9-11).

Various nondestructive examination (NDE) methods were completed to inspect the printed components. Control
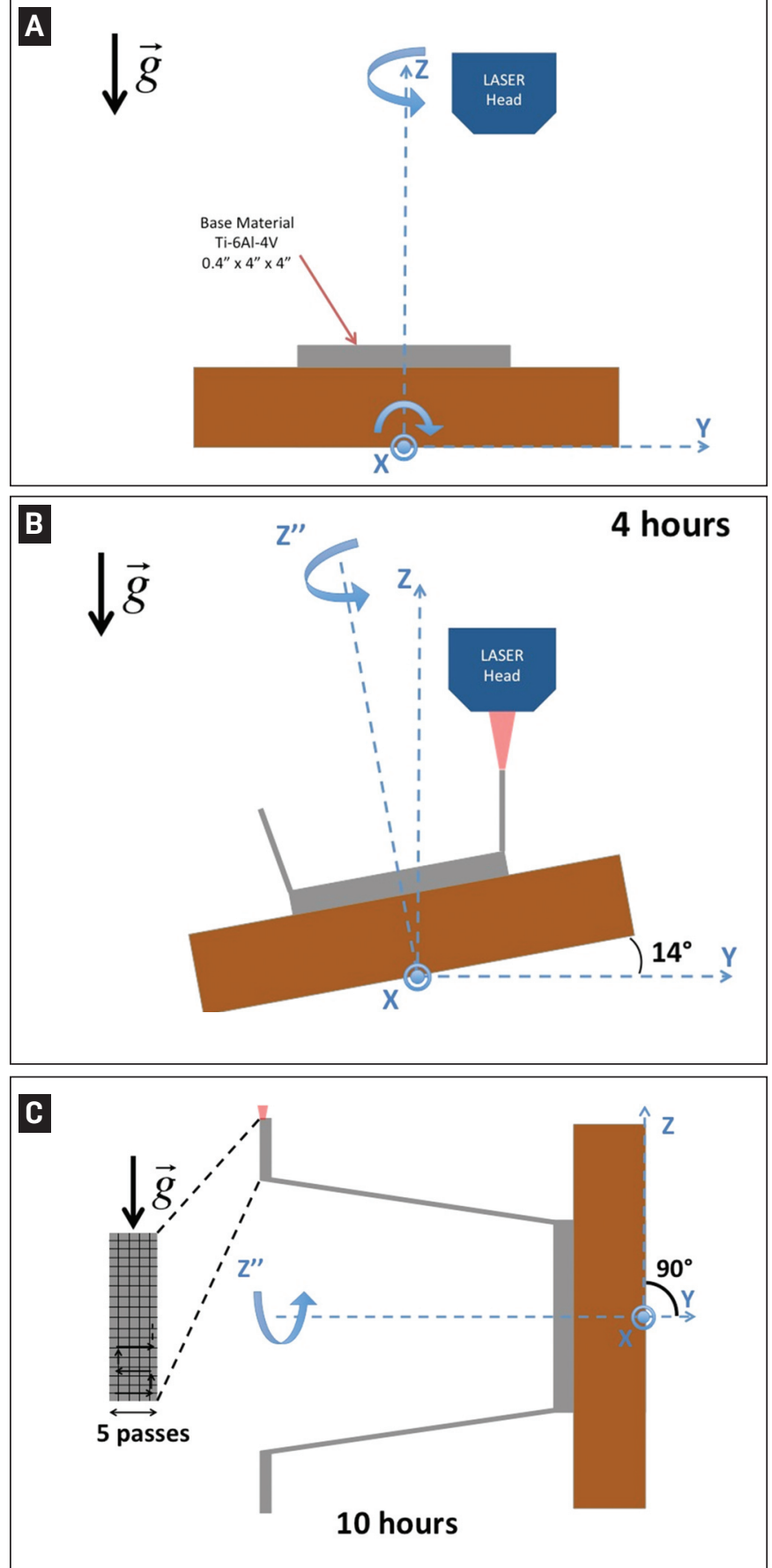

Fig. 2 - Printing strategy of the selected part: A - Initial position of the substrate; $B$ - followed by the printing of the cone; and $\mathrm{C}$ - ending by the printing of the flange.

of the printed geometry was done using a Spectrum (Carl Zeiss, Jena) coordinate measuring machine (CMM) associated with a Surveyor Laser Probe 250 (Laser Design Inc., Minneapolis, Minn.) for generating the three-dimensional point clouds. Data was analyzed using the Geomagic Control software. Prints were also inspected for common LWD structural defects, including porosity and incomplete fusion (Refs. $12,13)$, by means of radiographic testing (RT) and fluorescent penetrant inspection (FPI). Finally, average surface 


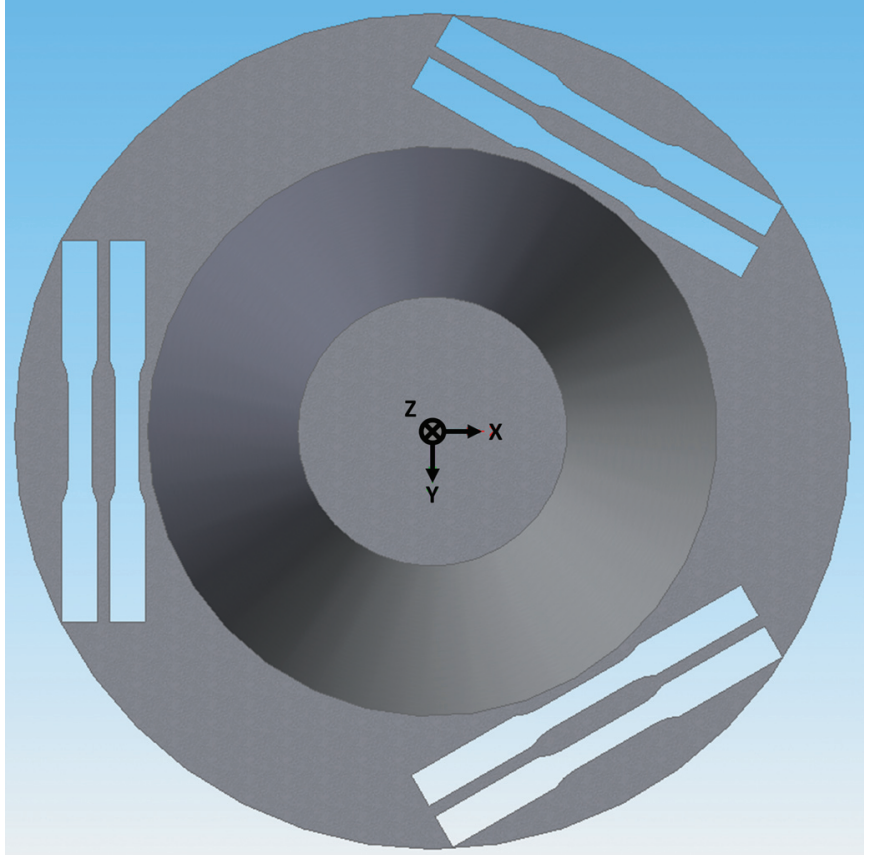

Fig. 3 - Static tensile sample extraction.

roughness $(\mathrm{Ra})$ was measured using a Surftest SJ-210 (Mitutoyo, Sakado, Japan).

Microstructures were evaluated using a Nikon light optical microscope equipped with a Clemex Vision system. All samples were mounted in bakelite. These samples were ground up to $1200 \mathrm{SiC}$ grit, followed by polishing with 3 - and $1-\mu \mathrm{m}$ diamond suspension and a finish with $0.05-\mu \mathrm{m}$ colloidal silica. Grinding and polishing were done using a Buehler Ecomet-3 autopolisher equipped with an Automet ${ }^{\circledR} 2$ head. Kroll's Reagent etchant with $91 \%$ deionized water $\left(\mathrm{H}_{2} 0\right), 6 \%$ nitric acid $\left(\mathrm{HNO}_{3}\right)$, and $3 \%$ hydrofluoric acid (HF) was then used on the mounted samples to reveal the structural features using the optical microscope. Fractographs were generated using a Hitachi SU-3500 scanning electron microscope. The Vickers hardness was measured by means of a Clark Microhardness (CM-100AT) indenter, using a 100-g load. A minimum of ten measurements were done along the build direction for each of the reported values.

Six machined, subsize flat specimens following ASTM E8, Standard Test Methods for Tension Testing of Metallic Materials, requirements with a thickness of $5 \mathrm{~mm}$, a gauge width of 6.35 $\mathrm{mm}$, and a gauge length of $25.4 \mathrm{~mm}$ were extracted from the flange region, as shown in Fig. 3. Samples were tested by an independent, approved testing facility at room temperature and with a crosshead speed of $2.54 \mathrm{~mm} / \mathrm{min}$. Average values of wrought tensile properties produced from five specimens extracted from the base plate and reproducing the small-size specimen geometry previously described have been used to normalize all the results.

\section{Results and Discussion}

\section{Printing Strategy}

A printing strategy needs to be adopted to efficiently pro-

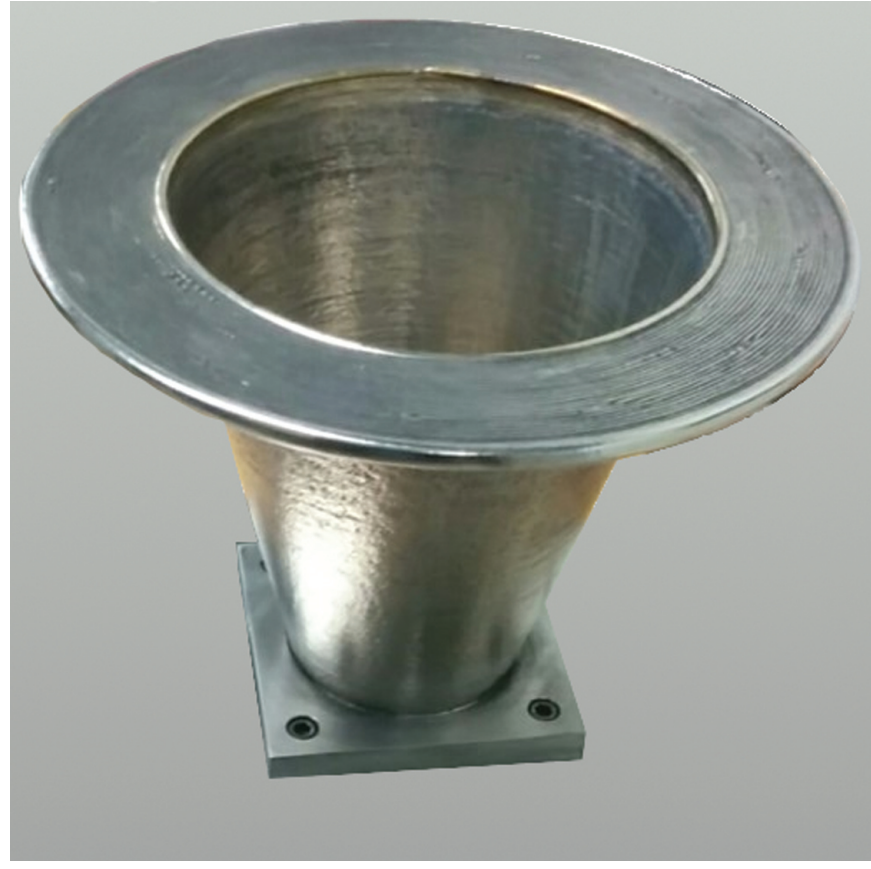

Fig. 4-Ti-6Al-4V as-built part produced by LWD.

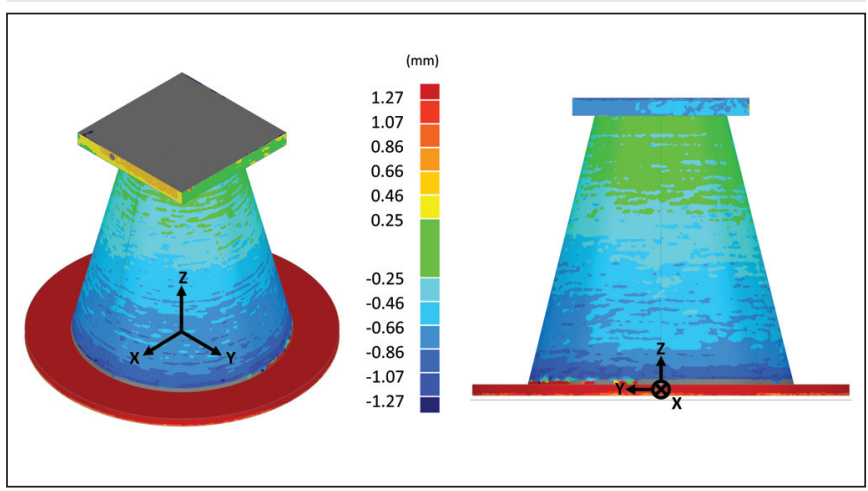

Fig. 5- Offset of the printed part with the as-built CAD geometry.

duce the part. Using an open source powder bed fusion (PBF) slicing software to generate the laser head path is not a viable option for this type of applications for two main reasons. First, the physics of the melt pool are different between PBF and LWD processes. Laser wire deposition produces larger melt-pool volumes than PBF processes and is associated with higher deposition rates and heat inputs (Refs. 6, 14). As a consequence, the melt-pool motion can encounter increased resistance when printing more advanced geometries, such as cones, spheres, or more complex free-form surfaces. In turn, nonoptimized motion of the deposition head could end up in a mismatch of the printed part geometry when compared to the computer-aided design (CAD) geometry. This issue is in part related to the second reason why common PBF slicing software can't be used efficiently in DED processes. These software only take into account the three main degrees of freedom in space available in PBF systems, which are the $\mathrm{x}^{-}, \mathrm{y}^{-}$, and $\mathrm{z}$-axes and the associated coordinated motions. In this context, a part as seen in Fig. 1A becomes extremely challenging to produce with 

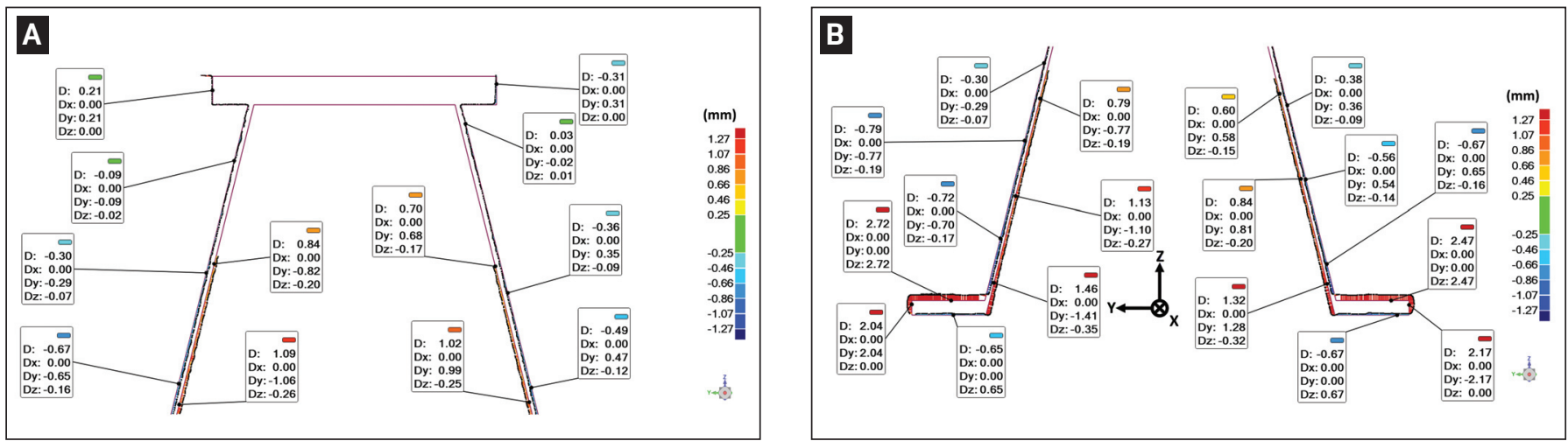

Fig. 6 - Transverse cut of the offset between the printed component and the as-built CAD model: A - In the substrate and cone regions; $B-$ in the flange and cone regions.
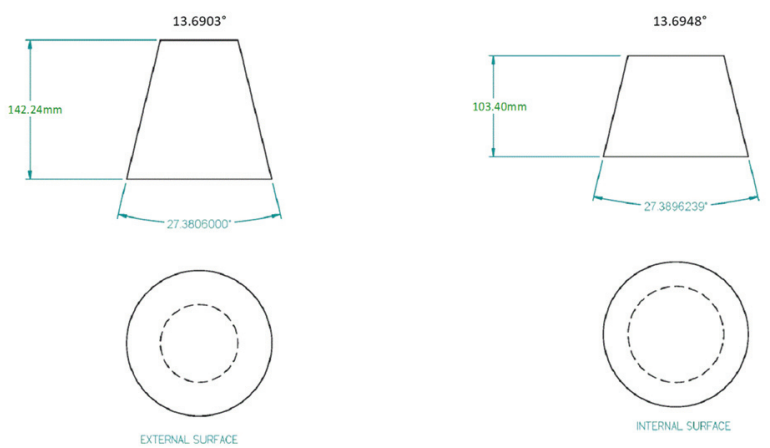

Fig. 7-Reconstructed internal and external cone surfaces of the printed component.

DED processes due to the presence of overhanging structures that would require the addition of large support structures, increasing lead times, and the BTF ratio. Parts with steep angles could also be problematic to produce, such as those characterized by the cone angle because of the lack in support of the generated melt pool.

However, degrees of freedom in DED systems can easily exceed the three degrees of freedom available in PBF systems. In addition to the traditional coordinated motions using the $\mathrm{x}^{-}, \mathrm{y}^{-}$, and $\mathrm{z}$-axes, the part itself can be potentially rotated around any of the available axes in their fixed or tilted positions. This is a nonnegligible advantage when compared with PBF applications in that printed surfaces can be reoriented in space to use them as new starting substrates, as described in the Experimental Methods section, by dividing the part into the three distinct regions.

The final printed part is shown in Fig. 4. An average Ra of $9.8 \mu \mathrm{m}$ was achieved along the build direction, while an average Ra of $3.8 \mu \mathrm{m}$ was measured orthogonal to the build direction. These results are similar to the average surface roughness derived in the literature for LWD (Ref. 13), as opposed to PBF processes that are typically associated with an average $\mathrm{Ra}$ in the range of 25 to $40 \mu \mathrm{m}$ and mostly induced by the presence of unmelted satellite particles bonded to the external surfaces (Refs. 13, 15-17). This process resulted in a substantial decrease of the BTF ratio with a value of 3.2, reducing the required amount of machining by $89 \%$ when compared to conventional subtractive processes. Next, the part underwent a heat treatment associating an annealing cycle below the $\beta$ transus temperature and an aging cycle that derived the best combination of mechanical properties in previous studies (Refs. 10, 11).

\section{Evaluation of the Printed Component}

Next, all the required nondestructive and destructive examination were done to validate the geometrical and structural integrity of the printed component.

\section{Geometrical Integrity}

The offset of the generated point cloud to the as-built CAD geometry and with regard to the selected coordinated system is first shown in Fig. 5. The CMM-generated map revealed a gradual negative gradient of deposited material on the external surface of the printed cone, reaching a maximum value of about $-1.3 \mathrm{~mm}$ at the connection with the flange. The flange was characterized on the opposite with an excess of deposited material of about $1.3 \mathrm{~mm}$.

A transverse cut of the offset maps in Fig. 6A and B show that an opposite positive gradient of the deposited material exists on the internal surface of the printed cone. The presence of this gradient could be explained by two reasons: an accumulation of residual stresses that would have induced plastic deformation, or a slight shift in the tilt angle resulting in a change of the cone angle. To confirm one or the other hypothesis, the internal and external printed cone surfaces were reconstructed from the generated point clouds, as shown in Fig. 7. A transverse cut of these surfaces unveiled straight linear walls. The slope of these surfaces with regard to the vertical axis was then measured at 13.6903 and 13.6948 deg for the external and internal surfaces, respectively. These results suggest that the geometrical shift between the printed part and the as-built CAD model is induced by a slight shift in the tilt angle, and not plastic deformation. The printed part geometry still remains within the CAD tolerance set at \pm 0.5 deg.

Thicknesses of the deposits in the cone and flange regions were then evaluated in Fig. $8 \mathrm{~A}$ and $\mathrm{B}$. These results show that thicknesses of the different regions were mostly 

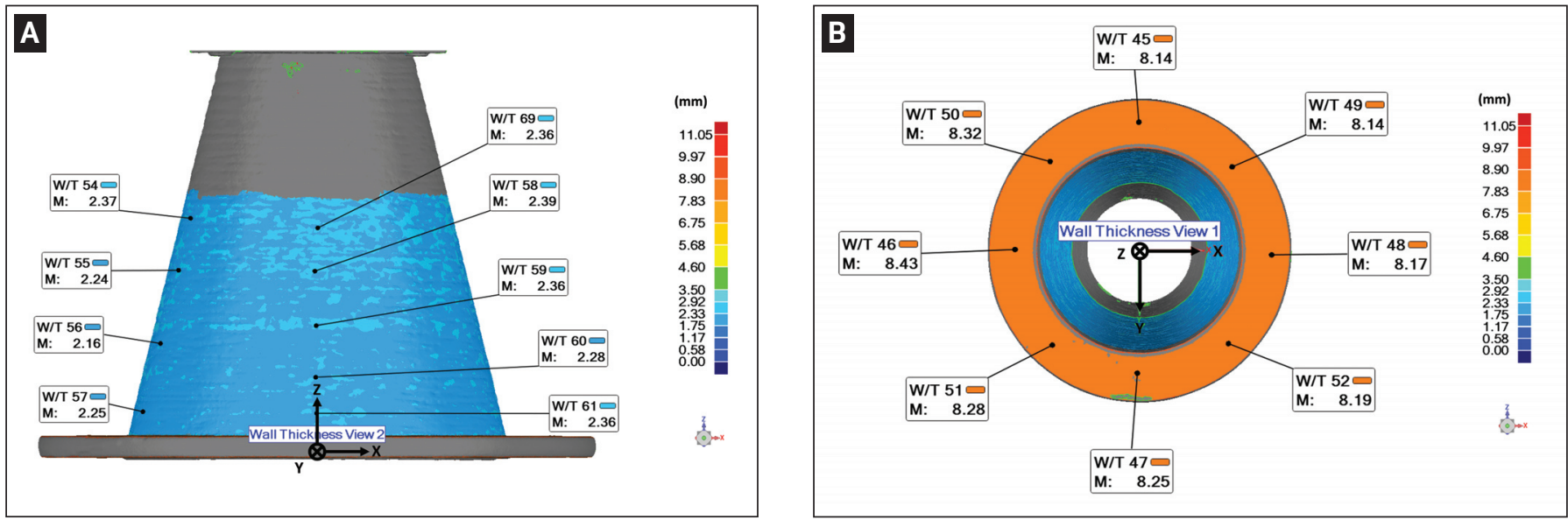

Fig. 8 - Evaluation of the (A) cone and (B) flange thicknesses. All dimensions are in $\mathrm{mm}$.

constant with about $2.3 \mathrm{~mm}$ for the cone wall and $8.2 \mathrm{~mm}$ for the flange. These measurements are important to ensure that enough material was deposited prior to the machining of the surface. The machining of the surface served two objectives by meeting the final geometry requirements of the CAD model and ensuring a good surface finish. The knowledge of the slope of the printed cone wall along with the knowledge of the thicknesses of the different regions enabled the successful machining of the part surface, as shown in Fig. 9D. Eventually, structural integrity of the print was investigated using RT and FPI. Both NDE procedures produced negative results.

\section{Macrostructure Evolution}

A second prototype was built using the same deposition parameters to evaluate the developed structure and properties of the component through destructive examination. The different macrostructures within the different regions of the part are shown in Fig. 9.

No clear macrostructural features can be observed from the substrate in Fig. 9A. This is mainly due to the bimodal initial microstructure characterizing the wrought substrate. The cone region was characterized by the presence of prior $\beta$ grains, as shown in Fig. 9B. This is a well-reported feature in the literature (Refs. 9-11, 14, 18, 19) associated with the strongly directional heat extraction and the preferential solidification direction of the $\beta$ phase. The heat treatment cycles were beneficial in removing the banding phenomenon associated with the complex thermal history of the deposi- tion process and typically observed in the as-built condition (Refs. 9, 11). Width of the prior $\beta$ grains within the cone region was assessed at $1.4 \pm 0.5 \mathrm{~mm}$, as shown in Table 1 . This is smaller than what was measured in a previous study using the same deposition parameters (Ref. 9). It can be explained by the fact that heat transfer in this case is completely different from the one presented in the previous study (Ref. 9) in part due to the dimensions of the selected part along with the continuous deposition of material during the cone printing. This is also reflected within the flange region in Fig. 9C. Here, the prior $\beta$ grains width was measured at about $0.8 \pm$ $0.4 \mathrm{~mm}$, which is considerably smaller than the size of the prior $\beta$ grain that developed in a previous study (Ref. 11). In this case, the lower number of deposited beads within one layer and the active cooling by convection with the surrounding argon atmosphere induced by the rotation of the part during the deposition could also be beneficial in reducing the prior $\beta$ grain size.

\section{Microstructure Evolution}

Typical microstructures that were observed within the part are shown in Fig. 10. A typical mix of $\alpha$ platelets in between globular $\alpha$ grains can be observed within the substrate in Fig. 10A. The main dimensional features of each of the regions are presented in Table 1 . No major differences have been observed between different areas of a same region, as seen in Fig. 10B-F, extracted from equally spaced regions within the cone starting closer to the substrate in Fig. 10B and ending closer to the flange in Fig. 10F. Similarly,

Table 1 - Dimension of Some Key Macro- and Microstructural Features

\begin{tabular}{|c|c|c|c|c|c|}
\hline Region & $\begin{array}{l}\text { Prior } \beta \text { Grain } \\
\text { Width }(\mathrm{mm})\end{array}$ & $\begin{array}{c}\alpha \text { Platelets } \\
\text { Thickness } \\
(\mu \mathrm{m})\end{array}$ & Width $(\mu \mathrm{m})$ & $\begin{array}{c}\text { Globular } \alpha \\
\text { Height }(\mu \mathrm{m})\end{array}$ & Aspect Ratio \\
\hline Substrate & - & $1.3 \pm 0.4$ & $9.6 \pm 3.0$ & - & $\approx 1$ \\
\hline Cone & $1.4 \pm 0.5$ & $2.1 \pm 0.5$ & $8.1 \pm 3.0$ & $29.0 \pm 10.9$ & $3.6 \pm 1.9$ \\
\hline Flange & $0.8 \pm 0.4$ & $2.3 \pm 0.5$ & $7.6 \pm 1.5$ & $29.9 \pm 10.0$ & $3.9 \pm 1.5$ \\
\hline
\end{tabular}



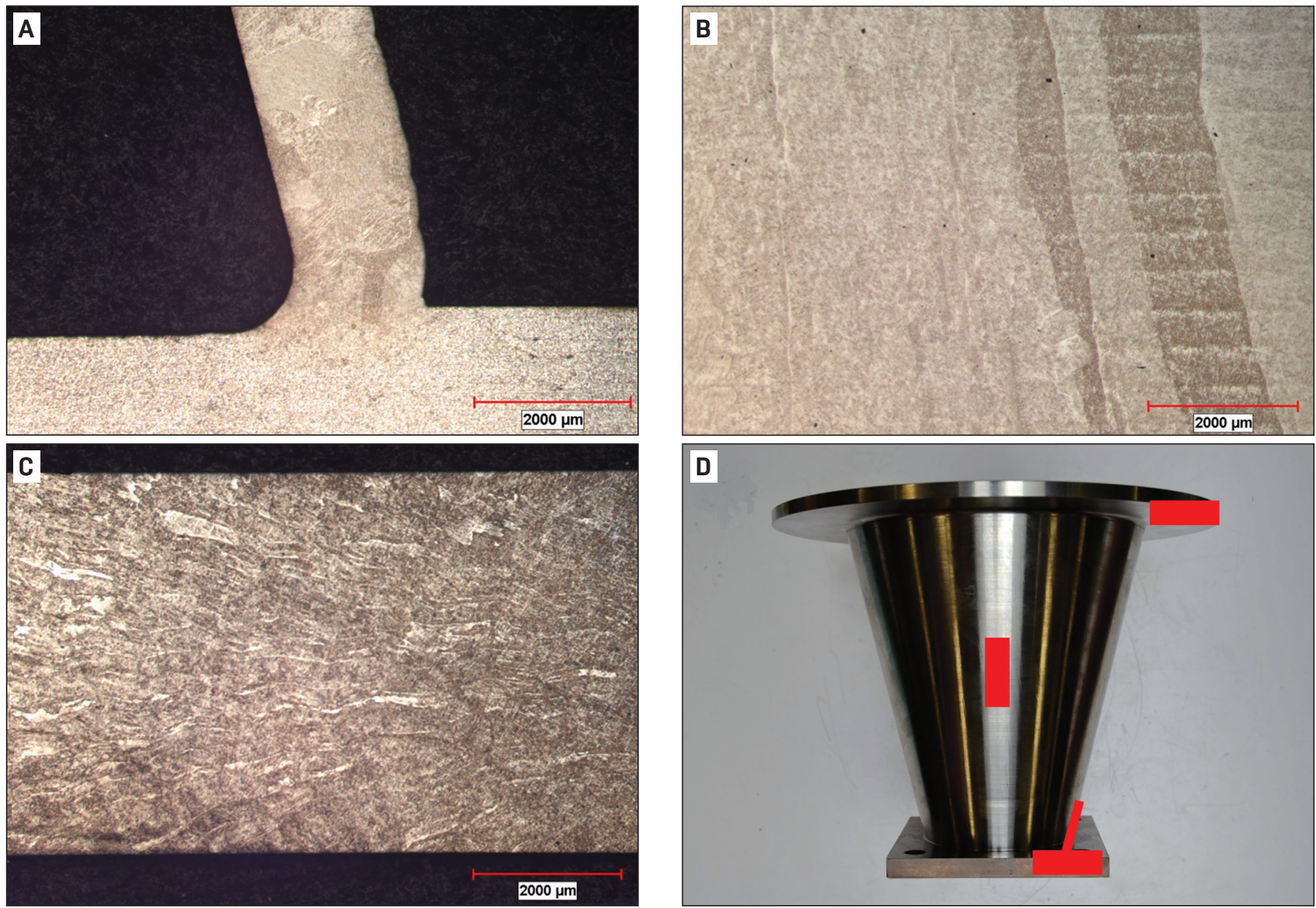

Fig. 9-Macrostructure of the following: $A$ - Cone connection to the substrate; $B$ - cone region; $C$ - flange region; $D-$ respective position of each of the previous micrographs.

Table 2 - Hardness Measurements

$\begin{array}{cc}\text { Region } & \text { Hardness (HV) } \\ \text { Substrate } & 341 \pm 9 \\ \text { Cone } & 303 \pm 11 \\ \text { Flange } & 299 \pm 6\end{array}$

Fig. 10G was extracted closer to the first deposited layers within the flange region, while Fig. $10 \mathrm{H}$ was closer to the last deposited layers. The annealing heat treatment induced a coarsening of the microstructure for which $\alpha$ platelets were about $2 \mu \mathrm{m}$ thick, as seen in Table 1 . This value is similar to the values generated in previous studies (Refs. 10, 11). Globular $\alpha$ grains with an average aspect ratio comprised between 3.6 and 3.9 were observed distributed all over the buildup. A higher concentration of these globular $\alpha$ grains were observed in the flange region than in the cone region. This could be associated with slower cooling rates experienced by the flange region induced by the deposition pattern in this region. Moreover, two prior $\beta$ grain boundaries in the cone region are shown in Fig. 10C and $\mathrm{E}$ and pointed out by red arrows. No grain boundary allotriomorphs $\alpha_{\mathrm{GB}}$ were observed, but rather a network of $\alpha$ platelets extending from either side attesting of the higher cooling rates experi- enced by the cone region following the deposition process. A typical prior $\beta$ grain boundary observed in the flange region is shown in Fig. 10H. It is associated with the presence of a grain boundary allotriomorph $\alpha_{\mathrm{GB}}$, as pointed out by red arrows and colonies of $\alpha$ platelets extending on each side. Both of these last microstructural features were also observed in a previous study (Ref. 11).

\section{Mechanical Properties}

Typical hardness values measured within the different regions of the printed part are shown in Table 2 . The cone and the flange regions developed similar hardness. These values are similar to the reported values in other studies (Refs. 10, 11). A higher hardness has been measured within the substrate. The change in microstructure is most probably one of the reasons for this increased hardness. This is also in line with the typically higher strengths developed in the wrought condition.

Static tensile properties from the flange region are provided in Table 3 . Due to the coarsening of the microstructure and the morphology and arrangements of the $\alpha$ phase within the $\beta$ matrix (Refs. 10,11), generated results were below the typical strengths generated in the wrought condition. However, the tested samples were characterized with a 

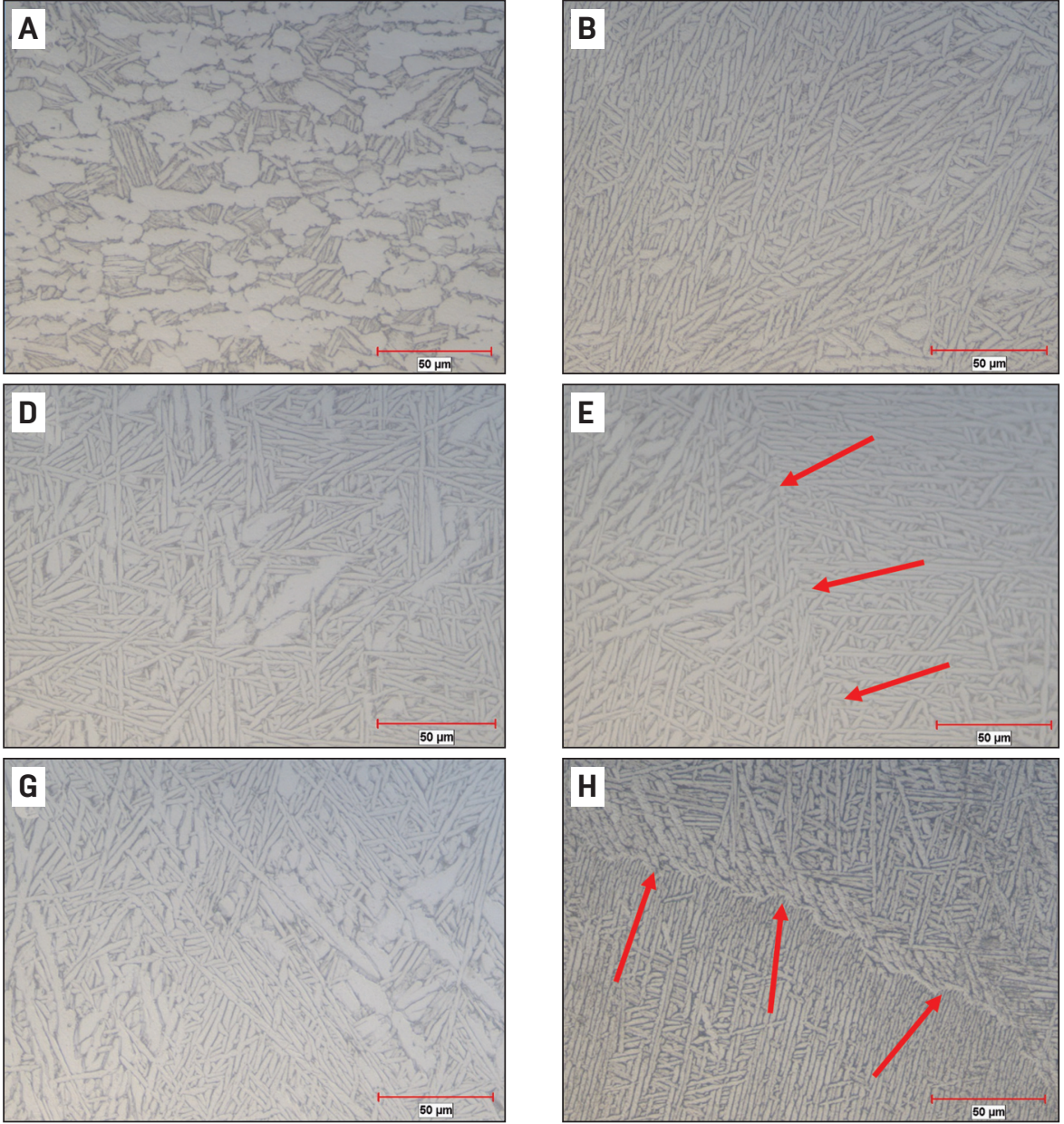

Fig. 10 - High-magnification optical micrographs of typical microstructures within the printed part: $A-$ Bimodal microstructure within the substrate; $B-F-$ microstructures at different levels within the cone region starting closer to the substrate and ending closer to the buildup; and microstructures within the flange region (G) starting closer to the first deposited layers and $(H)$ ending closer to the last deposited layers.

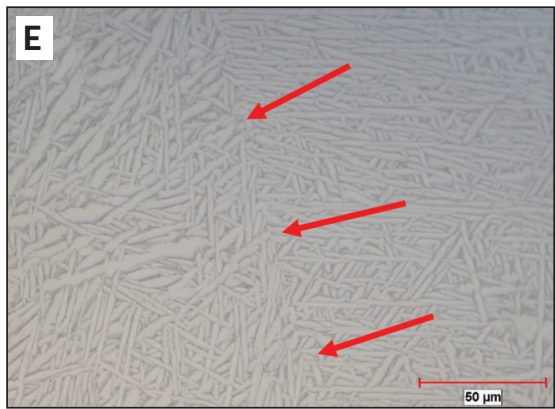

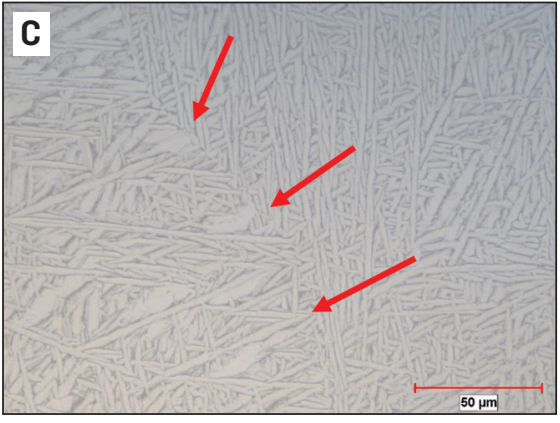

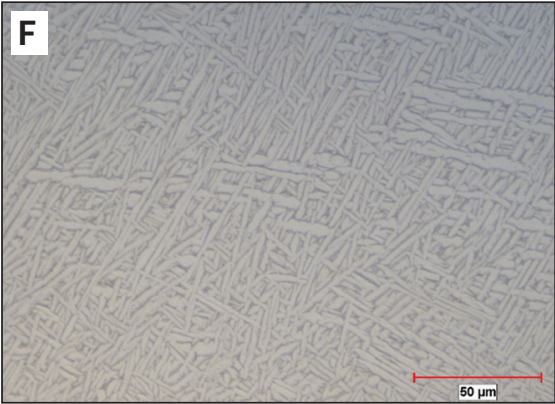

gation in lamellar studies. The higher magnification SEM fractographs in Fig. $11 \mathrm{~B}$ and $\mathrm{C}$ also revealed the presence of a healthy population of dimples at the fracture surface, which supports the good elongation derived in Table 3. A transgranular type of fracture characterizes the tested samples as seen in Fig. 11D and E. No signs of prior $\beta$ grain boundaries have been observed at higher magnification in Fig. $11 \mathrm{~F}$, suggesting again that fracture propagation was driven by the sample's microstructure. The extent of necking that can be observed in Fig. 11A and D is in agreement with the data in Table 3.

Testing of tensile samples from the cone region was also attempted. However,

very good elongation, consistently exceeding the minimum wrought requirements as set by AMS4911, Titanium Alloy, Sheet, Strip, and Plate, 6Al-4V, Annealed. This was also supported by the good reduction of area measured following the testing, and is presented in Table 3.

Scanning electron microscope (SEM) and optical microscope fractographs in Fig. 11 provided more insight on the tested samples fracture mechanisms. Microstructural features are believed to mostly drive the propagation of the crack front, resulting in the fracture surface shown in Fig. 11A. This is in agreement with observations made in a previous study (Ref. 11) and by the study of Buirette et al. (Ref. 20) on crack propascattering of the results in terms of strength and elongation prevented the authors from extracting any conclusions. These poor results are believed to be induced by the nonconstant curvature of the cone combined with the grips of the machine that did not match their geometries, yielding complex strength distributions within the tensile specimens during their testing, thus ending in nonuniaxial solicitations.

\section{Machined Part}

Eventually, machining of the part to the drawing require-

Table 3 - Flange Room Temperature Static Tensile Properties

\begin{tabular}{lccc}
$\begin{array}{c}\text { Yield Strength } \\
\left((\mathrm{MPa} / \mathrm{MPa})^{*} 100\right)\end{array}$ & $\begin{array}{c}\text { Ultimate Tensile Strength } \\
\left((\mathrm{MPa} / \mathrm{MPa})^{*} 100\right)\end{array}$ & $\begin{array}{c}\text { Elongation } \\
\left((\% / \%)^{*} 100\right)\end{array}$ & $\begin{array}{c}\text { Reduction of Area } \\
(\%)\end{array}$ \\
\hline $71.8<74.8<76.9,2.0$ & $76.0<78.0<80.0,1.5$ & $67.2<86.7<123.1,19.0$ & $12<35.3<49,15.5$ \\
\hline
\end{tabular}

*Results are presented as $\sigma_{\min }<\bar{\sigma}<\sigma_{\max }$, standard deviation (SD) where $\sigma_{\min }$ is the lowest value, $\bar{\sigma}$ is the mean value, $\sigma_{\max }$ is the highest value, and $\mathrm{SD}$ is the standard deviation from the mean value. 

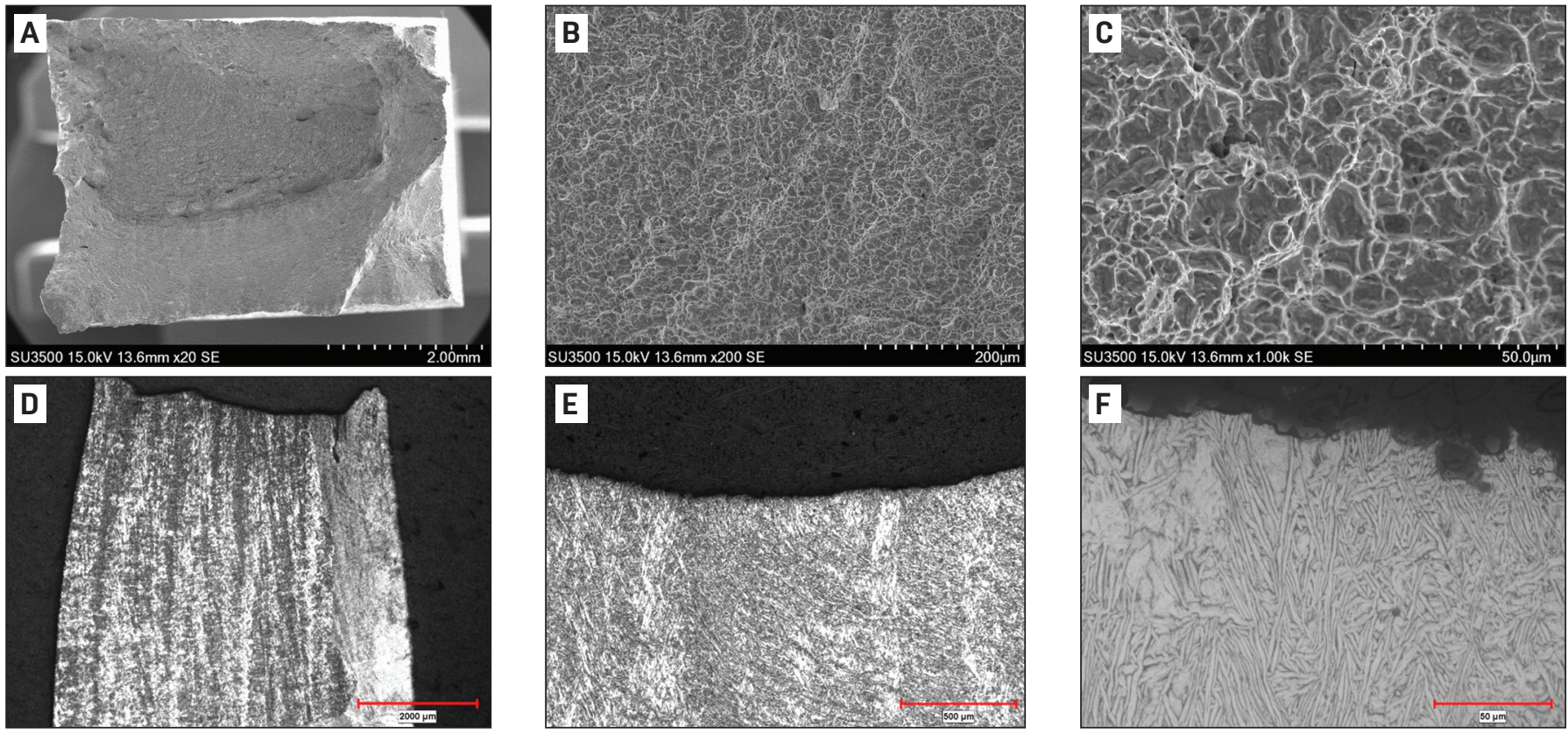

Fig. $11-A-$ Low-magnification SEM fractograph of the static tensile specimen; B and C - higher-magnification SEM of the fracture surface; $D$ - optical macrograph of the fracture surface; $E$ - low-magnification optical micrograph of the fracture surface; $F$ - high-magnification optical micrograph of the fracture surface.

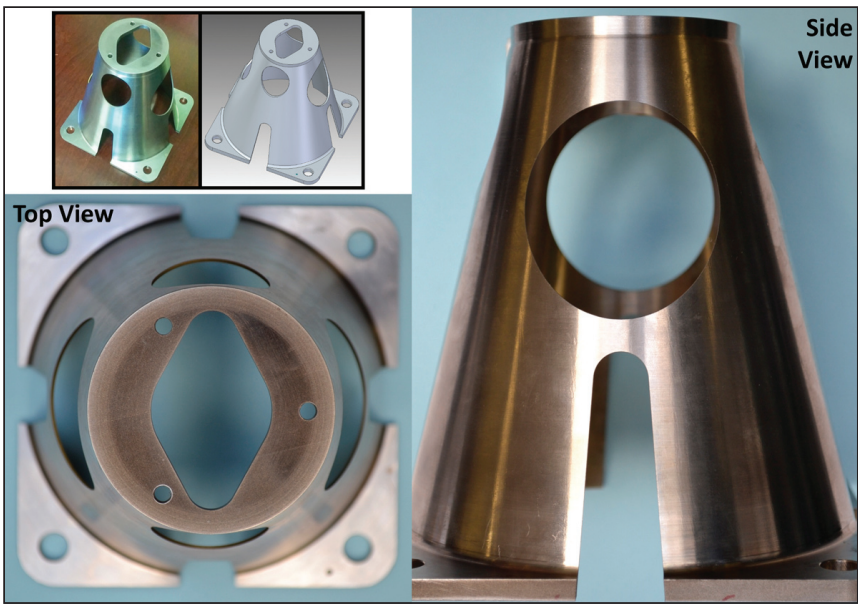

Fig. 12 - Ti-6Al-4V machined prototype following the LWD printing process and the heat treatment cycles.

ments was successfully completed through multiple processes including electrical discharge machining, drilling, and computer numerical control machining. The final result is shown in Fig. 12.

\section{Conclusion}

All the necessary steps to successfully print a large Ti6Al-4V aerospace component were presented in this study. First, the printing strategy in the as-built condition, the selection of deposition parameters, and the selection of heattreating cycles were presented. The additional degrees of freedom available in the LWD process allowed the authors to fully take advantage of the available symmetries and simple geometries that characterized the selected part. The BTF ra- tio was reduced from 30.8 to 3.2. A nondestructive examination of the printed part using a CMM revealed the key geometrical features when compared to the as-built CAD geometry. The geometrical investigation enabled the successful machining of the surface of the prototype in the first step. Next, various destructive tests were done to examine the developed microstructure and subsequent mechanical properties. The annealing and aging heat cycles did not impact the morphology of the developed prior $\beta$ grains. They induced an important coarsening of the microstructure that resulted in a reduced strength within the flange region when compared to the typical wrought values, but were associated with good elongation exceeding the minimum wrought requirement as set by the AMS4911 specification. Hardness values were higher within the substrate when compared with the rest of the buildup and mainly associated with the change in microstructure from bimodal to lamellar. Eventually, machining of the part was successfully completed to the drawing requirements.

\section{Acknowledgments}

The authors would like to thank the Consortium de Recherche et d'Innovation en Aérospatiale au Québec (CRIAQ), Liburdi, Centre de Métallurgie du Québec, Bell Helicopter Textron Canada, Bombardier, Edmit, General Electric, Héroux-Devtek, MDA, and Pratt \& Whitney Canada for their project contribution under the CRIAQ MANU601/NSERC CRD grant.

\section{References}

1. Lütjering, G., and Williams, J. C. 2007. Titanium, $2^{\text {nd }}$ ed. New York: Springer. 
2. Froes, F. H. S., Gungor, M. N., and Imam, M. A. 2007. Costaffordable titanium: The component fabrication perspective. JOM 59(6): 28-31. DOI: 10.1007/s11837-007-0074-8

3. Gibson, I., Rosen, D. W., and Stucker, B. 2010. Additive Manufacturing Technologies 3D Printing, Rapid Prototyping, and Direct Digital Manufacturing, $2^{\text {nd }}$ ed. New York: Springer.

4. Chua, C. K., and Leong, K. F. 2014. 3D Printing and Additive Manufacturing Principles and Applications, $4^{\text {th }}$ ed. Singapore: World Scientific

5. Leyens, C., and Peters, M. 2003. Titanium and Titanium Alloys: Fundamentals and Applications. Weinheim: Wiley-VCH.

6. Thompson, S. M., Bian, L., Shamsaei, N., and Yadollahi, A. 2015. An overview of direct laser deposition for additive manufacturing; Part I: Transport phenomena, modeling and diagnostics. Additive Manufacturing 8: 36-62.

7. Qiu, C., Ravi, G. A., Dance, C., Ranson, A., Dilworth, S., and Attallah, M. M. 2015. Fabrication of large Ti-6Al-4V structures by direct laser deposition. Journal of Alloys and Compounds 629: 351-361. DOI: 10.1016/j.addma.2015.07.001

8. Baufeld, B. 2011. Effect of deposition parameters on mechanical properties of shaped metal deposition parts. Journal of Engineering Manufacture 226: 126-136. DOI: 10.1177/ 0954405411403669

9. Chekir, N., Tian, Y., Gauvin, R., Brodusch, N., Sixsmith, J., and Brochu, M. 2018. Effect of travel speed and stress relief on thin Ti-6Al-4V laser wire deposits. Materials Science \& Engineering A 724: 335-347. DOI: 10.1016/j.msea.2018.03.101

10. Chekir, N., Tian, Y., Sixsmith, J., and Brochu, M. 2018. Effect of travel speed and sub- $\beta$ transus post deposition heat treatments on thin laser wire deposits. Materials Science \& Engineering A 724: 376-384. DOI: 10.1016/j.msea.2018.03.100

11. Chekir, N., Tian, Y., Gauvin, R., Brodusch, N., Sixsmith, J., and Brochu, M. 2018. Laser wire deposition of thick Ti-6Al-4V buildups: Heat transfer model, microstructure, and mechanical properties evaluations. Metallurgical and Materials Transactions A 49(12): 6490-6508. DOI: 10.1007/s11661-018-4927-2

12. Åkerfeldt, P., Pederson, R., and Antti, M.-L. 2016. A fractographic study exploring the relationship between the low cycle fatigue and metallurgical properties of laser metal wire deposited $\mathrm{Ti}$ 6Al-4V. International Journal of Fatigue 87: 245-256. DOI:

10.1016/j.ijfatigue.2016.02.011

13. DebRoy, T., Wei, H. L., Zuback, J. S., Mukherjee, T., Elmer, J. W., Milewski, J. O., Beese, A. M., Wilson-Heid, A., De, A., and
Zhang, W. 2018. Additive Manufacturing of metallic components - Process, structure and properties. Progress in Materials Science 92: 112-224. DOI: 10.1016/j.pmatsci.2017.10.001

14. Shamsaei, N., Yadollahi, A., Bian, L., and Thompson, S. M. 2015. An overview of direct laser deposition for additive manufacturing; Part II: Mechanical behavior, process parameter optimization and control. Additive Manufacturing 8: 12-35. DOI: 10.1016/ j.addma.2015.07.002

15. Edwards, P., and Ramulu, M. 2014. Fatigue performance evaluation of selective laser melted Ti-6Al-4V. Materials Science \& Engineering A 598(26): 327-337. DOI: 10.1016/j.msea.2014.01. 041

16. Chan, K. S., Koike, M., Mason, R. L., and Okabe, T. 2013. Fatigue life of titanium alloys fabricated by additive layer manufacturing techniques for dental implants. Metallurgical and Materials Transactions A 44(2): 1010-1022. DOI: 10.1007/s11661-012-1470-4

17. Wang, P., Sin, W. J., Nai, M. L. S., and Wei, J. 2017. Effects of processing parameters on surface roughness of additive manufactured Ti-6Al-4V via electron beam melting. Materials 10(10): 1121. DOI: 10.3390/ma10101121

18. Baufeld, B., Brandl, E., and Van der Biest, O. 2011. Wire based additive layer manufacturing: Comparison of microstructure and mechanical properties of Ti-6Al-4V components fabricated by laser-beam deposition and shaped metal deposition. Journal of Materials Processing Technology 211(6): 1146-1158. DOI: 10.1016/ j. jmatprotec.2011.01.018

19. Brandl, E., Schoberth, A., and Leyens, C. 2012. Morphology, microstructure, and hardness of titanium (Ti-6Al-4V) blocks deposited by wire-feed additive layer manufacturing (ALM). Materials Science and Engineering A 532: 295-307. DOI: 10.1016/j.msea. 2011.10.095

20. Buirette, C., Huez, J., Gey, N., Vassel, A., and Andrieu, E. 2014. Study of crack propagation mechanisms during Charpy impact toughness tests on both equiaxed and lamellar microstructures of Ti-6Al-4V titanium alloy. Materials Science \& Engineering A 618: 546-557. DOI: 10.1016/j.msea.2014.09.048

NEIB CHEKIR and MATHIEU BROCHU are with the Department of Mining and Materials Engineering, McGill University, Montreal, Quebec, Canada. J. J. SIXSMITH and ROBERT TOLLETT are with Liburdi Automation Inc., Dundas, Ontario, Canada.

\section{Authors: Submit Research Papers Online}

Peer review of research papers is now managed through an online sytem using Editorial Manager software. Papers can be submitted into the system directly from the Welding Journal page on the AWS website (aws.org) by clicking on "submit papers." You can also access the new site direclty at editorialmanager.com/wj/. Follow the instructions to register or log in. This online system streamlines the review process, and makes it easier to submit papers and track their progress. By publishing in the Welding Journal, more than 70,000 members will receive the results of your research.

Additionally, your full paper is posted on the American Welding Society website for FREE access around the globe. There are no page charges, and articles are published in full color. By far, the most people, at the least cost, will recognize your research when you publish in the world-respected Welding Journal. 